\title{
An Observational and Comparative Study of Diurnal Variation of Spirometry Test Parameters among First and Second Year Normal and Healthy Medical Undergraduate Students
}

\author{
Neelima Kumari ${ }^{1}$, Ashutosh Kumar ${ }^{2}$, Manish Kumar ${ }^{3}$ \\ ${ }^{1}$ Associate Professor, Department of Physiology, Katihar Medical College, Katihar, ${ }^{2}$ Professor, \\ Department of Microbiology, Patna Medical College \& Hospital, Patna, ${ }^{3}$ Associate Professor, \\ Department of Pharmacology, IGIMS, Patna
}

\begin{abstract}
Introduction: This study was designed to assess and compare diurnal variability of FEF25, FEF50, FEF75, FEF25-75, PEF and FEV1 by measuring these parameters during morning and evening hours in normal healthy subjects.

Materials and Method: 190 students were enrolled and divided intogroupsof 8-10 students. Each group were directed to appear at different dates in Pulmonary Function Test (PFT) Laboratory at 7:30 AM and again at 5:00 PM for spirometry testing. Spirometry was performed with Spiro Excel 1.1 as per the ATS guidelines and by trained technician. Finally, data from 169 subjects was found to be complete and appropriate and was taken for the analysis.Diurnal variability in FEF25, FEF50, FEF75, FEF25-75, PEF and FEV1 were determined and compared.

Results: Allparameters were more in male than female. All the parameters were significantly high in evening tests as compared to morning tests except FVC. Diurnal variability among different spirometry parameters was significantly different (ANOVA, $\mathrm{p}<0.05$ ) in morning and evening tests. The diurnal variability was highest in large airways as reflected by FEF75 and lowest in smaller airways as reflected by FEF25. The diurnal variability was lowest for FEV1\%. It revealed that all parameters exhibit significant diurnal variability.
\end{abstract}

Conclusion: FEV1, FEF and PEF had shown diurnal variability which was directly related to the airway calibre. Greater variability was seen in PEF as compared to FEV1 i.e. proximal airways showed greater diurnal variation than distal airways.

Keywords: Spirometry test, Pulmonary Function Test, Diurnal variability, FEV1, PEF.

\section{Introduction}

Variability in calibre of airways is a normal

\section{Corresponding Author:}

\section{Dr. Manish Kumar}

Associate Professor, Department of Pharmacology, Indira Gandhi Institute of Medical Sciences,

Patna-800014, Bihar

Mobile No.: 9304093698

e-mail:manu072@gmail.com physiological process in normal personsand this variability may become exaggerated in patients of asthmatic and chronic obstructive pulmonary disease (COPD).Measurement of bronchial hyper-reactivity and airways variability has always posed challenge performing experiments on pulmonary function. Variability in peak expiratory flow (PEF) has been suggested as indicator for bronchial hyper-reactivity. ${ }^{[1-8]}$

The phenomenon of nocturnal asthma has always perplexed clinician's and researcher's mind. Peak expiratory flow rate (PEFR) variability has been 
suggested as a marker for bronchial hyper-reactivity in asthmatic individuals. ${ }^{[9,10]}$ PEFR variation has been widely advocated and used in clinical practice and asthma research. The National Heart Lung and Blood Institute (NHLBI) and others have recommended, a diurnal variation of $20 \%$ or more, as a diagnostic benchmark for asthma. ${ }^{[11,12]}$

Airway function exhibit variability over 24-h periods. This variability has a base that lung function gets worse at night in nocturnal asthma patients and to a lesser extent with COPD..$^{[13-16]}$ As nocturnal asthma is common and troublesome, ${ }^{[13,14,17]}$ circadian variation in airway function has been of considerable interest in respiratory medicine. It has been recognized that diurnal variation in airway calibre occurs in healthy subjects as well. ${ }^{[18-20]}$

It has been suggested that diurnal variation of PEFR in excess of $20 \%$ can be used for diagnosis of bronchial asthma in remission where routine spirometry may not show any significant obstructive defect. [19,21] Previous studies mentioned that PEFR shows time to time variation with respect to day and night cycle with specific pattern of lowest at early morning and highest at evening in normal as well as in asthmatics. ${ }^{[6,7,22]}$ PEFR variation has been widely advocated and used in clinical practice and asthma research.

Several evidences suggest that airway variability exhibits a definite circadian pattern in which morning PEF levels are lower than daytime values, with a minimum in early morning and peak in evening. ${ }^{[6,7,22,23]}$ The pattern of variability is exaggerated in smokers and in COPD and in asthmatic patients. ${ }^{[6]}$

The various spirometry indices reflect airflow characteristics of different airways. Forced expiratory flow (FEF), at $25 \% \mathrm{FVC}$, i.e. FEF25 reflects small airways, at $75 \%$ FVC (FEF75) reflects large airways and at 50\% FVC (FEF50) reflects mid/small airways. FEF from $25 \%$ to $75 \%$ FVC (FEF25-75), reflects mid/ small airways and is also known as mid expiratory flow. Forced expiratory volume in one second (FEV1) reflects the calibre of both large and small airways, whereas PEF is more a reflection of the calibre of large airways. ${ }^{[24,25]}$ In general FEV1 is a more reliable indicator of airflow limitation than PEF. [26]

Unfortunately, most studies that describe diurnal variability in airways calibre in asthmatics have used PEF rather than FEV1. Moreover, the diurnal variability of small, mid and large airways has not been studied systematically. This study was designed to assess and compare diurnal variability of FEF25, FEF50, FEF75, FEF25-75, PEF and FEV1 by measuring these parameters during morning and evening hours in normal healthy subjects.

\section{Materials and Method}

Study Site/Place: This study was conducted in the Department of Physiology of Katihar Medical College, Katihar.

Study Duration: September 2018 to February 2019 (Six months).

\section{Inclusion Criteria:}

1. First and second year MBBS students

2. 17 to 30 years of age and all the gender

3. Healthy students having almost similar daily routine

\section{Exclusion Criteria:}

1. Students have history of smoking.

2. History of severe chest trauma, with chest and spinal deformity.

3. Personal/family history of asthma, chronic obstructive pulmonary diseases and

4. Personal/family history of other cardiovascular and/ or respiratory diseases.

Study Design: An observational and prospective study.

190 students, 100 from first and 90 from second year MBBS batch students were selected for this study after considering inclusion and exclusion criteria. The study protocol was duly approved by Head of the Department of Physiology and Pharmacology. After enrolment students were explained about the study.A thorough clinical history was taken and anthropometric measurements (height and weight) were recorded. Brief clinical examination was done to rule out any obvious cardio-pulmonary compromise.

The Pulmonary Function Test was done using Digital Spirometer Machine (Spiro Excel 1.1 by Medicaid Systems). Parameters which had been interpreted like Forced Expiratory Volume in 1 second (FEV1), Peak Expiratory Flow(PEF), Forced Vital Capacity (FVC), Forced Expiratory Flow (FEF), Forced Expiratory Time (FET) and Flow/Volume Curves. 
Enrolled students were divided into different groups with 8-10 students in a group. Each group were directed to appear at different dates in Pulmonary Function Test Laboratory at 7:30 AM and again at 5:00 PM for spirometry testing. Spirometry was performed with Spiro Excel 1.1 by trained technician between 7:30 to 8.00 AM in morning and 5:00-5:30 PM in evening. PFT was done as per the ATS guidelines ${ }^{[27]}$ The test curve with the highest sum of the FVC and FEV1 were taken for further analysis.

Recorded data was scrutinized and any incomplete or inadequate test record was rejected. Finally, data from 169 subjects was found to be complete and appropriate and was taken for the analysis.

Statistical Analysis: Paired t-test was used to analyse and compare FEV1, FEF25, FEF50, FEF2575 , FEF75 and FVC values obtained from morning and evening tests of each student. Diurnal variation (dv) i.e. difference between morning and evening values of all parameters for each student were calculated as mean $\pm \mathrm{SD}$. The Diurnal variabilities of different parameters were compared using one-way analysis of variance. The statistical analysis was performed by Instat GraphPad Software. A p-value $\leq 0.05$ was considered as significant.

\section{Results}

Out of enrolled 190 students,data of 169 students were analysed. Male $(n=96)$ and female $(n=73)$ ratio was 1.32:1. Mean age of all students was $24.48 \pm 3.12$. Mean height and mean weight of students was $168.22 \pm 8.68$ and $60.37 \pm 10.42$ respectively.

Table 1: Anthropometric and Spirometrydata (Mean \pm SD) between male and female students measured at 7:30 AM

\begin{tabular}{|l|c|c|}
\hline Basal Parameters & Males $(\mathbf{n = 9 6})$ & Females $(\mathbf{n}=\mathbf{7 3})$ \\
\hline Age & $24.68 \pm 3.20$ & $24.10 \pm 3.28$ \\
\hline Height & $171.85 \pm 8.06$ & $157.04 \pm 5.12$ \\
\hline Weight & $63.88 \pm 11.14$ & $54.07 \pm 9.23$ \\
\hline FEF25 & $7.08 \pm 1.12$ & $6.46 \pm 1.31$ \\
\hline FEF25-75 & $4.06 \pm 0.81$ & $3.48 \pm 0.87$ \\
\hline FEF50 & $4.47 \pm 0.92$ & $3.75 \pm 0.80$ \\
\hline FEF75 & $1.97 \pm 0.49$ & $1.68 \pm 0.58$ \\
\hline FEV1 & $3.84 \pm 0.41$ & $3.11 \pm 0.33$ \\
\hline FVC & $4.49 \pm 0.48$ & $3.56 \pm 0.29$ \\
\hline FEV1\% & $85.06 \pm 4.97$ & $86.57 \pm 5.37$ \\
\hline PEF & $9.15 \pm 1.11$ & $8.21 \pm 0.96$ \\
\hline
\end{tabular}

Table 2: Spirometry parameters $(\mathrm{Mean} \pm \mathrm{SD})$ recorded in all students $(\mathrm{n}=169)$ in morning $(7: 30 \mathrm{AM})$ and in evening (5:00 PM) and their diurnal variability

\begin{tabular}{|c|c|c|c|c|c|}
\hline Parameter & Morning Values & Evening Values & p value & Diurnal Variability & p value \\
\hline FEF25 & $6.90 \pm 1.21$ & $7.09 \pm 1.24$ & HS & $7.83 \pm 6.23$ & $\mathrm{~S}$ \\
\hline FEF25-75 & $3.88 \pm 0.86$ & $4.07 \pm 0.91$ & HS & $9.57 \pm 9.64$ & $\mathrm{~S}$ \\
\hline FEF50 & $4.28 \pm 1.04$ & $4.45 \pm 1.15$ & HS & $10.75 \pm 11.31$ & $\mathrm{~S}$ \\
\hline FEF75 & $1.89 \pm 0.54$ & $2.01 \pm 0.55$ & HS & $13.15 \pm 11.92$ & $\mathrm{~S}$ \\
\hline FEV1 & $3.64 \pm 0.52$ & $3.68 \pm 0.51$ & $\mathrm{~S}$ & $3.91 \pm 3.63$ & $\mathrm{~S}$ \\
\hline FEV1\% & $85.42 \pm 4.97$ & $86.63 \pm 4.86$ & HS & $3.25 \pm 2.90$ & $\mathrm{~S}$ \\
\hline $\mathrm{FVC}$ & $4.29 \pm 0.77$ & $4.32 \pm 0.76$ & NS & $4.27 \pm 4.90$ & $\mathrm{~S}$ \\
\hline PEF & $8.89 \pm 1.15$ & $9.11 \pm 1.10$ & HS & $6.42 \pm 5.78$ & $\mathrm{~S}$ \\
\hline
\end{tabular}

HS- highly significant $(\mathrm{p}<0.001)$ S- significant- $(\mathrm{p}<0.05)$, NS- not significant $(\mathrm{p}>0.05)$

All the spirometry parameters were significantly high in evening tests as compared to morning tests except FVC. Diurnal variability among different spirometry parameters was significantly different $($ ANOVA, $p<0.05$ ) in morning and evening tests. The diurnal variability was highest in large airways as reflected by FEF75 and Lowest in smaller airways as reflected by FEF25. The diurnal variability was lowest for FEV1\%. 


\section{Discussion}

Spirometry parameters had shown gender variation. All parameters were more in male than female. Showed a clear evidence that sex is a factor that affects PEF. ${ }^{[28]}$

Spirometry parameters exhibits circadian pattern andthey were less in morning compared to evening time. Diurnal variability may be seen due to variability in airway calibre during morning and evening time. ${ }^{[6,7,22,23]}$

Various studies have shown the diurnal variability of different spirometry parameters like Kondo S, Erban $\mathrm{J}$ et al. and Troyanov $\mathrm{S}$ et al. had demonstrated that spirometry parameters had significant difference during morning and evening time especially FEV1\% and PEF and consistent with the results obtained from present study. ${ }^{[29-31]}$

Present study had made an attempt to differentiate the diurnal variability in spirometry test due to change in calibre of proximal and distal airway using PEF and FEV1. Present study results were consistent withthe study done by Hegewald MJ et al., who had exhibited that intrinsic variability in a single session (both morning and evening) spirometry test was higher for PEF than FEV1 also diurnal variability of PEF was higher than FEV1 in healthy subjects. ${ }^{[32]}$

Changes in proximal airway calibre results in changes in PEF while changes in FEV1 is related to calibre of proximal and peripheral airway. ${ }^{[24]}$

Studies have interpreted that the variability in proximal airways is largely due to changes in airway geometry. Fractional reduction in large airway calibre leads to greater decrease in flow compared to smaller airways. And it occurs due to a theory according to that flow rate or resistance is inversely proportional to the fourth power of radius. Also, it is a fact that the proximal and distal airways differ in smooth muscle content and nerve supply. The density of nerve supply and smooth muscle mass decreases as we proceed from proximal to distal airways. ${ }^{[33]}$ This is why the diurnal variability in smaller airways is lower than larger airways.

Correlation between PEF and FEV1 and their diurnal variability was significant. This feature was representation of changes in proximal airways calibre corresponding to changes in distal airways calibre. Morning and evening mean of both PEF and FEV1 were significantly different and showed diurnal variability. Previous study also supported results of this study. ${ }^{[2,6,23]}$
FEV1 was clinically more suitable to know the diurnal variability because total variability was lowest and maximum variability seen was less than $10 \%$. Clinical use of Mid Expiratory Flow was not justified because it showed high variability. FEV1 and PEF showed variability according to the previous study.

\section{Conclusion}

FEV1, FEF and PEF has shown diurnal variability which was directly related to the airway calibre. Proximal airways showed greater diurnal variation than distal airways due to in their calibre, reflected by greater variability in PEF as compared to FEV1. In this study only two readings were taken to investigate the diurnal variability. Further study with multiple recordings in 24hour duration should be tried to better characterize the circadian pattern of spirometry parameters and exploring their physiological basis.

\section{Source of Funding: Self}

\section{Conflict of Interest: None}

\section{Ethical Clearance: Taken}

\section{References}

1. Nunn AJ, Gregg I. New regression equations for predicting peak expiratory flow in adults. BMJ. 1989 Apr 22;298(6680):1068-70.

2. Aggarwal AN, Gupta D, Chaganti S, Jindal SK. Diurnal variation in peak expiratory flow in healthy young adults. Indian J Chest Dis Allied Sci. 2000 Jan-Mar;42(1):15-9.

3. Siafakas NM, Vermeire P, Pride NB, Paoletti P, Gibson J, Howard P, Yernault JC, Decramer M, Higenbottam T, Postma DS, et al. Optimal assessment and management of chronic obstructive pulmonary disease (COPD). The European Respiratory Society Task Force. Eur Respir J. 1995 Aug;8(8):1398-420.

4. M R Hetzel. The pulmonary clock. Thorax. 1981 Jul; 36(7): 481-486. doi: 10.1136/thx.36.7.481.

5. Ryan G, Latimer KM, Dolovich J, Hargreave FE. Bronchial responsiveness to histamine: relationship to diurnal variation of peak flow rate, improvement after bronchodilator and airway calibre. Thorax 1982;37:4239.

6. Casale R, Pasqualetti P. Cosinor analysis of circadian peak expiratory flow variability in normal 
subjects, passive smokers, heavy smokers, patients with chronic obstructive pulmonary disease and patients with interstitial lung disease Respiration 1997 64:251-56.

7. Thiadens HA, De Bock GH, Dekker FW, Value of measuring diurnal peak flow variability in the recognition of asthma: a study in general practice Eur Respir J 1998 12:842-47.

8. VanKeimpema AR, Ariaansz M, Tamminga JJ, Nauta JJ, Postmus PE, Nocturnal waking and morning dip of peak expiratory flow in clinically stable asthma patients during treatment. Occurrence and patient characteristics Respiration 1997 64: 29-34.

9. Higgins BG, Britton JR, Chinn S, Cooper S, Burney PG, Tattersfield AE, Comparison of bronchial reactivity and peak expiratory flow variability measurements for epidemiologic studies Am Rev Respir Dis 1992 145:588-93.

10. Neukirch F, Liard R, Segala C, Korobaeff M, Henry C, Cooreman J, Peak expiratory flow variability and bronchial responsiveness to methacholine. An epidemiologic study in 117 workers Am Rev Respir Dis 1992 146:71-75.

11. National Asthma Education and Prevention Program. Expert panel report 2: Guidelines for the diagnosis and management of asthma. Bethesda, MD.: National Institutes of Health, 1997. (NIH Publication no. 97-4051).

12. Kunzli N, Stutz EZ, Perruchoud AP, Brandli O, Tschopp JM, Bolognini G, Karrer W, Schindler C, Ackermann-Liebrich U, Leuenberger P. Peak flow variability in the SAPALDIA study and its validity in screening for asthma-related conditions. The SPALDIA Team. Am J Resp Crit Care Med 1999; 160: 427-434.

13. Turner-Warwick, M. 1984. The definition and recognition of nocturnal asthma (with discussion). In P. J. Barnes and J. Levy, editors. Nocturnal Asthma. Oxford University Press, Oxford. 3-9.

14. Turner-Warwick, M. 1988. The management of chronic asthma. In P. J. Barnes, I. W. Rodger and N. C. Thomson, editors. Asthma: Basic Mechanisms and Clinical Management. Academic Press Limited, London. 721-732.

15. Anonymous. 1983. Asthma at night (editorial). Lancet 1:220-222.

16. Bateman, J. R. M. and S. W. Clarke. 1979. Sudden death in asthma. Thorax 34:40-44.

17. Storms, W. W., S. F. Bodman, R. A. Nathan and P. Byer. 1994. Nocturnal asthma symptoms may be more prevalent than we think. J. Asthma 31:313318.

18. Guberan, E., M. K. Williams, J. Walford and M. M. Smith. 1969. Circadian variation of F.E.V. in shift workers. Br. J. Ind. Med. 26:121-125.

19. Hetzel, M. R. and T. J. H. Clark. 1980. Comparison of normal and asthmatic circadian rhythms in peak expiratory flow rate. Thorax 35:732-738.

20. Kerr, H. D. 1973. Diurnal variation of respiratory function independent of air quality: experience with an environmentally controlled expo) sure chamber for human subjects. Arch. Environ. Health 26:144152.

21. Jamison JP, McKinley RK. Validity of peak expiratory flow rate variability for the diagnosis of asthma. Clin Sci (Lond) 1993;85:367-71.

22. Aggarwal AN, Gupta D, Kumar V, Jindal SK. Assessment of diurnal variability of peak expiratory flow in stable asthmatics. J Asthma 2002;39:487-91.

23. Goyal M, Goel A, Kumar P, Bajpai M, Verma NS, Kant S, Tiwari S, Circadian rhythm of peak expiratory flow rate in healthy north Indian men Indian J Physiol Pharmacol 2008 52:64-8.

24. Mead J, Problems in interpreting common tests of pulmonary mechanical function. In: Macklem P, Permutt S, editors The lung in transition between death and disease 1979 New York Marcel Dekker Inc.:43-51.

25. Ph.H Quanjer, G.J. Tammeling, J.E. Cotes, O.F. Pedersen, R. Peslin, J-C. Yernault. Lung volumes and forced ventilatory flows. European Respiratory Journal 1993 6: 5-40; DOI: 10.1183/09041950.005s 1693

26. Thiadens HA, De Bock GH, Van Houwelingen JC, Dekker FW, DeWaal MW, Springer MP. Can peak expiratory flow measurements reliably identify the presence of airway obstruction and bronchodilator response as assessed by FEV (1) in primary care patients presenting with a persistent cough? Thorax 1999 54:1055-60.

27. M.R.MILLERETAL.Standardisationofspirometry. Eur Respir J 2005; 26: 319-338. SERIES “ATS/ ERS TASK FORCE: STANDARDISATION OF LUNG FUNCTION TESTING" Edited by V. Brusasco, R. Crapo and G. Viegi Number 2 in this 
Series. DOI: 10.1183/09031936.05.00034805

28. Raju PS, Prasad KV, Ramana YV, Murthy KJ. Pulmonary function tests in Indian girls - Prediction equations. Indian J Pediatr 2004;71:893-7.

29. Kondo S. The amplitude of circadian FEV1 variation suitable for phase determination by cosinor analysis in stable asthmatic children. Chest 1992 Sept; 102: 771-74.

30. Erban J, Adamec M, The occurrence of circadian rhythm in respiration in healthy persons and in patients with bronchial asthma Cas Lek Cesk 1989 Dec; 8:1584-86.

31. Troyanov S, Ghezzo H, Cartier A, Malo JL, Comparison of circadian variations using FEV1 and peak expiratory flow rates among normal and asthmatic subjects Thorax 1994 Aug; 49 (8): 77580.

32. Hegewald MJ, Lefor MJ, Jensen RL, Crapo RO, Kritchevsky SB, Haggerty CL, Peak expiratory flow is not a quality indicator for spirometry: peak expiratory flow variability and FEV1 are poorly correlated in an elderly population Chest 2007 131:1494-99.

33. Larson SD, Schelegle ES, Hyde DM, Plopper CG. The three-dimensional distribution of nerves along the entire intrapulmonary airway tree of the adult rat and the anatomical relationship between nerves and neuroepithelial bodies Am J Respir Cell Mol Biol 2003 28:592-99. 